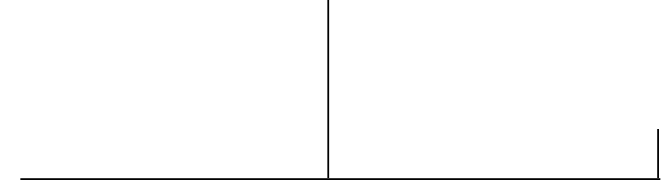

Rev. Latinoam. Psicopat. Fund., São Paulo, v. 11, n. 2, p. 239-253, junho 2008

\title{
Contrato narcisista e clínica do vazio*
}

\author{
Mario Rossi Monti
}

Na sociedade ocidental, a relação entre as gerações é modulada por um pacto narcisista implícito. As características desse pacto foram bem descritas por Piera Aulagnier e, antes disso, por Sigmund Freud em seu "Sobre o narcisismo: uma introdução". Nesse ensaio, Freud descreve a atitude dos pais em relação a seus filhos. Os pais clamam para seus filhos a ab-rogação de todas as leis da natureza e da sociedade (que limitam seu próprio narcisismo). Doença, morte, renúncia ao prazer, restrições não deveriam atingir seus bebês. Seus bebês aspiram ser "Sua majestade o bebê".

As "leis da natureza e da sociedade" são hoje muito diferentes em relação à época de Freud. Nas sociedades ocidentais, a criança realmente se tornou "Sua majestade o bebê". Que relação existe entre esse novo pacto narcisístico e as novas formas de psicopatologia que caracterizam a sociedade ocidental? A condição borderline e a depressão endêmica têm alguma relação com essa nova condição cultural e social na infância?

Palavras-chave: Psicopatologia, depressão, narcisismo, borderline

* Tradução de Roberta Barni. 


\section{Contrato narcisístico implícito}

Há muitos anos - se diz - as sociedades ocidentais já não se reconhecem numa cultura da culpa e do conflito quanto, antes, numa cultura do empreendimento e depois da iniciativa. A angústia da culpa foi substituída pela angústia da inadequação, do vazio, do déficit do desempenho, da insuficiência vexaminosa. Alain Ehrenberg (1998), em brilhantíssimo ensaio sobre as formas da depressão no mundo atual, falou em cansaço de ser si mesmos. De maneira parecida, Pierre Fédida (2001) propôs que se considerasse o fenômeno clínico da depressão como uma espécie de contrapartida negativa da valorização extrema do desempenho e da capacidade de estar plenamente à altura das próprias expectativas ideais, que o espírito da época nos impõe. Em suma, tornou-se um lugar-comum dizer que a cultura do pós-moderno é uma cultura do narcisismo. Nessa época parece ter sentido apenas ocupar-se de si mesmos ou das próprias realizações pessoais. Prevalece o individualismo, em detrimento da subjetividade. Muitas análises psicológicas ou sociológicas do fenômeno tendem, todas, à mesma conclusão: a atenção para a subjetividade, para a dimensão da espiritualidade deu lugar a uma visão materialista na qual os indivíduos são entidades separadas, dominadas pela indiferença e pelo impulso à auto-realização a qualquer preço.

Narcisismo, intimismo, hedonismo, tornaram-se as palavras-chave dessa "idade do vazio" (Lipovetsky, 1983) na qual um desencanto geral, uma "forma inédita de apatia, que se distingue por sensibilização epidérmica em relação ao mundo" conjuga-se com uma profunda indiferença. Essa verdadeira mutação antropológica realiza-se num clima de "apatia desenvolta" que, se provavelmente constitui um antídoto em relação à paranóia, presente em toda grande ideologia, ao mesmo tempo implica uma desagregação da identidade. Nessa condição de perene fluidez, na qual as coisas e as pessoas não parecem dotadas de forma própria, mas assumem, antes, a forma de seu recipiente, toda identidade vacila ou vive sua própria inconsistência. Nessa corrida rumo à "pluralização intrapsíquica dos sujeitos" decerto se abre a possibilidade de imaginar inúmeras identidades possíveis, transbordando daqueles vínculos com base nos quais, convencionalmente, atribuem-se os papéis; mas também se corre o risco de uma paralisia da identidade. Como reconhecer-se em uma identidade numa condição em contínua transformação e que remete sistematicamente a possibilidades infinitas? Se não ficarmos atônitos, perplexos e paralisados diante da vastidão de horizontes 
instáveis e cambiantes, que se abrem diante de cada um, só resta agarrar mais do que depressa - como diz Bauman (2003) - "identidades esvoaçantes" que, porém, logo depois se dissipam.

O narcisismo do qual pretendo falar aqui não é apenas o da cultura narcisista, em que todos nós estamos mergulhados, mas, antes, aquele que constitui o cerne de um contrato implícito: o contrato narcisístico. No que consiste esse contrato? Com esse termo Piera Aulagnier (1975) indicava a missão que pesa sobre cada recém-nascido assim que ele aparece. Assim que cada recém-nascido da espécie humana vê a luz, é investido numa missão. Uma missão que é parte daquela transmissão transgeracional dos fantasmas dos pais que assume o aspecto de um verdadeiro "fantasma no berçário". Um fantasma que vigia o recém-nascido, pondo-se ao lado de seu berço desde suas primeiras horas de vida (Fraiberg et al., 1975) e que encarna as expectativas, conscientes e inconscientes, que as gerações anteriores fazem com que pesem sobre ele e sobre sua vida inteira.

Mas para que serve esse contrato? Ele desempenha a função de um vínculo. Vincula cada geração com a anterior. Garante a continuidade entre as gerações, segundo uma modalidade peculiar, conjugada nos termos de um contrato implícito que é parte de uma economia narcisística. Cada recém-nascido ocupa um lugar dentro de um conjunto. Esse conjunto - para lhe assegurar um lugar - tem de investir narcisisticamente o recém-chegado. Esse investimento de caráter narcisista se dá dentro de uma cadeia da qual cada sujeito se sente membro reconhecido na medida em que é portador do sentido de pertença e de continuidade do grupo. O contrato narcisista, portanto, desempenha uma função tripla: assegura uma origem; mantém a continuidade entre as gerações e garante o desenvolvimento de um sentido de continuidade; garante ao recém-nascido, e ao futuro adulto, o direito de ocupar um lugar. Um direito que se fundamenta não apenas no veredicto dos pais, mas também no reconhecimento sobre que grupo, em seu conjunto, é assegurado ao recém-nascido enquanto filho daquele casal. Ao lado do vínculo de filiação narcisista que atua dentro do casal que gerou o recém-nascido, coloca-se, assim, a dimensão da filiação instituída (Guyotat, 1980): o reconhecimento, por parte de um grupo, de um vínculo de filiação que adquiriu uma dimensão social.

Os termos desse contrato haviam sido desenhados com grande acuidade e sensibilidade por Freud em "Introdução ao narcisismo" (1914) quando escrevia:

... se considerarmos a atitude daqueles pais especialmente ternos com seus filhos, temos de reconhecer que essa atitude é um novo despertar e uma reprodução do próprio narcisismo, do qual os próprios pais tinham desistido havia tempo (...) Ao mesmo tempo, esses pais também tendem a suspender, em favor da criança, todas as aquisições da civilização que seu próprio narcisismo fora obrigado a respeitar, e tornam a reivindicar, pela criança, privilégios dos quais tinham desistido 
havia tempo (...) Doença, morte, renúncia do prazer, restrições impostas à vontade pessoal não devem ter validade para ela; as leis da natureza e da sociedade devem ser revogadas em seu favor, ela deve mais uma vez se tornar realmente o centro e cerne da criação - aquela "Sua Majestade o Bebê" que outrora os pais se sentiam (...) No ponto mais vulnerável do sistema narcísico - a imortalidade do ego, que a realidade questiona tão fortemente -, se consegue segurança refugiando-se na criança. ${ }^{1}$ (tradução livre)

Dessa reflexão freudiana, gostaria de frisar quatro pontos fundamentais:

1. Os pais, quando um filho nasce, vivem uma reativação do próprio narcisismo infantil. Narcisismo do qual tinham desistido por causa dos vínculos e das limitações com que se depararam na vida adulta;

2. em nome dessa reativação, os pais fantasiam que seu bebê possa desfrutar de uma moratória. Como dizer que precisamente para ele todos aqueles limites impostos pela sociedade podem ser momentaneamente suspensos e não valerem. Em suma, os pais reivindicam para ele todos aqueles privilégios dos quais eles próprios, ao contrário, tiveram de desistir. Tudo o que se interpõe limitando a felicidade ou o bem-estar do homem deve ser alvo de moratória: doença, morte, renúncia do prazer, restrições e leis não devem valer para ele;

3. leis naturais e sociais devem ser revogadas. A criança se coloca no centro da criação como um pequeno soberano: sua majestade a criança;

4. diante da tomada de consciência de que a própria vida é alvo de pesados limites, até temporais, já que ninguém é imortal, os pais procuram segurança na criança, prolongando-se narcisicamente em sua vida.

\section{Doença, morte, renúncia ao prazer}

Se esse é o contrato narcísico implícito que regulou as relações entre as gerações desde a época de Freud, a impressão é que no mundo atual (ao menos na-

1. "If we look at the attitude of affectionate parents towards their children, we have to recognize that it is a revival and reproduction of their own narcissism, which they have long since abandoned (...) Moreover, they are inclined to suspend in the child's favour the operation of all the cultural acquisitions which their own narcissism has been forced to respect, and to renew on this behalf the claims to privileges which were long ago given up by themselves (...) Ilness, death, renunciation of enjoyment, restrictions on his own will, shall not touch him; the laws of nature and of society shall be abrogated in his favour; he shall once more really be the centre and core of creation - 'His Majesty the Baby', as we once fancied ourselves (...) At the most touchy point in the narcissistic system, the immortality of the ego, which is so hard pressed by reality, security is achieved by takin refuge in the child." S. Freud. "On narcissism: an introduction”, p. 90-91. 
quelas sociedades denominadas avançadas) alguma coisa importante deve ter acontecido, precisamente no âmbito do contrato narcísico. Para tentar compreender o que poderia ter mudado no contrato narcísico implícito, que vincula as gerações, vale a pena começar a tratar, mais do que do contrato em si, do cenário social e cultural em que o contrato havia sido implicitamente rubricado na época de Freud. O cenário - escrevia Freud - é um cenário no qual nos confrontamos com "doença, morte, renúncia ao prazer". Nos anos em que Freud escrevia essas palavras, muitos recém-nascidos morriam ao longo do primeiro ano de vida: no começo do século XX (na Itália, por exemplo) morriam 168 em cada mil. Em meados da década de trinta, morriam cem. Em 1975 morriam 20,5. Hoje morrem 4,3. Em todos os países avançados encontramos a mesma tendência.

Nesse novo contexto, pôr no mundo uma criança se tornou uma coisa bastante diferente do que era à época de Freud. Toda mãe, todo casal de pais, todo filho se confrontava quase invariavelmente com a morte de uma criança, especialmente na época perinatal. Hoje a morte de uma criança já se tornou um fato raro: tanto que, quando isso acontece, tende-se a raciocinar em termos de culpa. Se um recém-nascido morreu, deve haver um culpado, alguém deve ter errado. Enfim, a morte em época perinatal não é mais um fato inevitável ou vivido como "natural". Ao contrário, tornou-se "natural" pensar que o nascimento de uma criança não tem nada a ver com o risco de morte. Uma morte que atingia em grande medida o recém-nascido, mas que também dizia respeito à mãe: o medo que a mulher tinha (e tem) do parto se sustentava também no fato de que, com efeito, muitas mulheres morriam de parto ou de complicações a ele ligadas. Hoje já não é assim. A eventualidade de que o nascimento de um novo indivíduo implique em um evento lutuoso, enfim, é extremamente rara.

Mas em geral, porém, podemos afirmar que a pressão que em outros tempos - doença, morte, restrições e renúncia ao prazer - se exercia sobre cada bebê, agora diminuiu de forma extraordinária.

Talvez as leis da natureza e da civilização, cuja revogação os pais pediam para seus filhos, tenham sido realmente revogadas. Não só os limites temporais da vida humana se estenderam, mas também as restrições sociais e as leis que outrora regulavam a vida das crianças mudaram profundamente. Uma gama de possibilidades inimaginável na época de Freud abre-se diante das crianças de hoje: gozo e prazer parecem estar ao alcance da mão.

Dizer que atualmente a vida das crianças melhorou é dizer uma coisa óbvia. Igualmente óbvio é afirmar que se desenvolveu uma verdadeira cultura da infância: uma cultura dos cuidados infantis, da relação mãe-bebê e pais e filhos. Essa nova cultura se expressa em verdadeiros ritos sociais, como o preparo ritualizado do espaço que o recém-nascido ocupará: o espaço físico, como o seu quarti- 
nho pronto para recebê-lo, mas também o espaço mental dos pais, predispostos ao evento graças à freqüentação de cursos específicos para prepará-los a assumir a função de genitor. Uma cultura, enfim, que pressiona os pais desde a época anterior ao nascimento, ou até mesmo desde antes a concepção. Mas essa cultura da infância, na maioria das sociedades avançadas, resvala cada vez em direção a um verdadeiro culto da infância, marcado por uma extraordinária valorização da vida infantil. Poderíamos nos perguntar, retomando os termos da reflexão freudiana: será que a criança se tornou realmente "sua majestade, a criança"? Não é raro acontecer que em nossos ambulatórios encontremos pais tratados de maneira tirânica por suas crianças. Por crianças que não são soberanos bem-aventurados, mas que, ao contrário, exercem um poder quase sádico sobre seus pasmados pais.

A rapidez das transformações a que assistimos nessas últimas décadas corre o risco de fazer com que esqueçamos um passado que deixamos para trás a bem pouco tempo. Apenas duas notas, breves, para chamar a atenção sobre alguns aspectos.

Há pouco mais de cem anos Anton Tchekhov (1887) sublinhava o valor do progresso. Nem tanto pelas conquistas científicas ou tecnológicas a que levara, quanto, antes, pelo fato que trouxera consigo uma maneira diferente de cuidar das crianças: "... acreditei no progresso desde a infância", escrevia, "e não deixei de acreditar, pois a diferença entre quando me batiam de chicote e quando deixaram de me chicotear foi enorme". Um progresso que Tchekhov vivera, é literalmente o caso de dizer, na própria pele.

O historiador Hugh Cunningham (1995) em seu Children and childhood in western society since 1500 recorda que no início dos anos 30 do século XIX, o governo britânico, no âmbito de uma tratativa sobre a duração do horário de trabalho, não cedeu às reivindicações por uma jornada de trabalho de 10 horas. Apesar disso, o governo havia acatado a solicitação para as crianças "proibindo o seu trabalho nas fábricas se tivessem menos de nove anos, e limitando a oito horas por dia o trabalho das crianças de até 14 anos". Naquela época, de fato, não se considerava viável levar adiante o trabalho industrial sem poder contar com o trabalho das crianças entre nove e 14 anos! O penoso entrelaçamento entre infância e trabalho só foi se dissolver há pouco tempo, em pequena porém significativa parte do mundo, por meio da tomada de consciência de que trabalho e infância são termos antitéticos: se há trabalho não há infância. Tanto que o termo "trabalho infantil", foi dito, deve ser considerado um verdadeiro oximoro: se há trabalho não pode haver infância, e vice-versa.

Aliás, basta ouvir os relatos de nossos avôs ou mesmo de nossos pais para encontrar vestígios de um mundo que hoje desconhecemos. Meu pai, por exem- 
plo, nasceu em 1923, e narra que ele e seus colegas, quando freqüentavam a escola primária, podiam "admirar" pelas paredes da classe a seqüência fotográfica relativa à execução, por enforcamento, de Cesare Battisti: um herói nacional italiano da Primeira Guerra Mundial. Trata-se de uma série de fotos nas quais o condenado à morte foi retratado antes, durante e depois da execução, cercado pelo carrasco e seus colaboradores, sorridentes e orgulhosos de seu trabalho. ${ }^{2}$ Quem poderia tolerar, hoje, que seu filho fosse pedagogicamente exposto a tamanha abominação numa sala de aula do ensino fundamental?

\section{Monumentalização da infância e psicopatologia}

Se o pano de fundo diante do qual se celebrara aquele contrato narcísico implícito, do qual Freud falava, mudou tanto assim, é altamente provável que as novas condições culturais e sociais nas quais vivemos tenham implicado uma nova negociação desse contrato. Parece realmente, em suma, que a condição de suspensão das leis da natureza e da sociedade que se pretendia para os próprios filhos na época de Freud hoje seja não só um augúrio expresso pelos pais, mas que tenha se tornado parte de um novo contrato social implícito. A criança - prosseguia Freud - tem de ter uma sorte melhor daquela de seus pais: não deve ser obrigada a padecer as renúncias e as necessidades que, como os pais sabem, dominam a vida. Hoje, todavia, a renúncia às próprias aspirações não é sentida como uma necessidade inevitável, e sim como um ataque injustificado à liberdade e aos direitos do indivíduo: "o mal-estar da pós-modernidade", escreve Bauman (2000), "deriva de uma busca pelo prazer tão desinibida que é impossível conciliá-la com aquele mínimo de segurança que o indivíduo tenderia a exigir".

O genitor - escrevia ainda Freud - consegue segurança no ponto mais vulnerável do sistema narcísico, vale dizer, em relação à imortalidade do ego, tornada radicalmente incerta pela realidade, refugiando-se na criança: entregando-lhe um trono do qual tomar posse.

Entretanto, o que acontece quando esse trono - não mais tão ameaçado pelas limitações que a realidade da época impunha - se torna um trono de verdade? Um trono real do qual se torna difícil descer. Um trono do qual não se pode descer é mais uma armadilha do que um trono. Não uma etapa mais ou menos fugaz de um percurso evolucional ao longo do qual nos confrontamos com uma progressiva decepção. Antes, um trono que se torna ponto de chegada. Uma prisão? Esta

2. As imagens de toda a seqüência da execução podem ser vistas no site: http:// www.kaiserjaeger.com/it/Albums_Cesare_Battisti.htm 
idealização permanente da infância, essa monumentalização que enfatiza as infinitas potencialidades evolucionais não acabará pesando nos ombros de Sua Majestade? Não fará com que ele esqueça que, embora sentado no trono mais prestigioso do mundo - como dizia Montaigne - está, ainda assim, sentado apenas sobre a própria bunda? Na medida em que esse trono é uma armadilha, não fará com que apareça a angústia de que fala Edgar Morin (2002) quando escreve que o ser humano "ao se tornar tudo, tem, ao mesmo tempo, consciência de não ser nada". Em que medida essa sensação de ser tudo e não ser nada tem a ver com aquele manto depressivo inespecífico que envolve as queixas de nossos pacientes? Cada vez mais freqüentemente, de fato, os clínicos contam que há algumas décadas seus pacientes mudaram. Não são mais os mesmos. Queixam-se de um sofrimento generalizado, pouco estruturado, que não se encaixa nas categorias descritivas que a psiquiatria predispôs há certo tempo. Chamamos tudo isso de "depressão". Mas essa palavra se tornou tão inespecífica que tem cada vez menos significado. Talvez as queixas genericamente "depressivas" que ouvimos de nossos "novos" pacientes poderiam vir de pessoas fechadas numa espécie de trono-armadilha? Em que medida os pacientes vazios e "deprimidos" dos quais com cada vez maior freqüência nos falam psicanalistas, psiquiatras e psicólogos clínicos são pessoas traumatizadas por esta monumentalização da infância?

Nos últimos anos do século passado Elisabeth Roudinesco (1999), como muitos outros, colocou-se o problema de como mudaram os pacientes dos psicanalistas. Os pacientes do final do século XX - essa é sua conclusão - se parecem pouco com aqueles graças aos quais a psicanálise surgiu. São, antes, pacientes "conformes à imagem da sociedade depressiva em que vivem. Impregnados pelo nihilismo contemporâneo, apresentam distúrbios narcísicos ou depressivos e sofrem de solidão e de sintomas de perda de identidade".

O panorama que se oferece ao ponto de vista dos psicanalistas é bastante nítido: há muitos anos os psicanalistas trabalham em torno da tentativa de encontrar modalidades mais eficazes de trabalho com pacientes muito diferentes daqueles em torno dos quais sua teoria e sua técnica nasceram. Precisamente porque os pacientes dos psicanalistas são uma absoluta minoria no panorama das disciplinas psicológico-psiquiátricas, é natural perguntar se as observações que os psicanalistas formularam de seu ponto de observação concordam (ou, ao contrário, contrastam) com aqueles realizados a partir de outros pontos de observação. Especificamente: mudaram, e em caso positivo, como mudaram, os pacientes dos Serviços de psiquiatria? Mesmo desse contexto chegam sinais similares àqueles registrados pelos psicanalistas. Por exemplo, os serviços de psiquiatria comunitária estão cada vez mais empenhados no tratamento de pacientes com distúrbios de personalidade, particularmente da área borderline e narcísica. 
Se há 25 anos os pacientes com personalidades anômalas ou psicopáticas eram consideradas pessoas que simplesmente "eram assim mesmo", maneiras de ser não passíveis de mudança (e portanto não pertencentes ao âmbito da psiquiatria, por não padecerem de nenhuma "doença"), hoje as coisas já não são assim.

Miguel Benasayag e Gérard Schmit (2003) trabalham no Serviço para distúrbios psicológicos da adolescência na França. De seu ponto de observação notaram uma dramática mudança qualitativa do sofrimento mental. E lançaram um grito de alerta. Ao pedido de ajuda que se manifesta nas formas clássicas descritas pela psicopatologia, pela psiquiatria e pela psicologia clínicas - escrevem - hoje se acrescenta e se sobrepõe um novo tipo de pedido. Um pedido de ajuda disseminado que se origina da percepção de um mal-estar genérico que os operadores não têm condições de enfrentar, quer de um ponto de vista quantitativo (pela amplidão do fenômeno) quer de um ponto de vista qualitativo (pela nova natureza do fenômeno). Até porque o tipo de pedido que lhes é dirigido é alguma coisa para a qual não receberam formação. "Atualmente", escrevem, "na França, assim como em outros países, milhares de jovens acompanhados por suas famílias literalmente perambulam de uma instituição a outra, de uma consulta a outra, carregando um fardo pesado de sofrimento e patologia". Tanto que nossos Serviços "se transformaram, aos poucos, numa espécie de funil em que se verte a tristeza disseminada que caracteriza a sociedade contemporânea".

Esse conjunto de sintomas se configura aos olhos de alguns como uma nova patologia (ou um conjunto de novas patologias, se não forem verdadeiras doenças). Nessa ótica, a nosografia psiquiátrica mais uma vez se lançou ao encalce da descrição e da definição dessas novas entidades. Mas, mais do que diante de um conjunto de sintomas e de doenças, estamos diante de uma mistura de experiências e no máximo de síndromes que representam os pontos de agregação de um sofrimento que pertence ao indivíduo isoladamente, mas também, e concomitantemente, à sociedade e à cultura na qual o indivíduo está inserido. As novas formas em que o sofrimento mental do indivíduo se configura parecem constituir o lugar em que esse sofrimento disperso precipita em constelações de experiências patológicas individuais. A prática clínica nos Serviços de psiquiatria comunitária permite captar os presságios, até maciços, desses novos fenômenos psicopatológicos. Em 1984, na Itália, o psicanalista Gaddini tinha enfatizado como o sofrimento individual podia, aos poucos, perder o sentido diluindo-se no funcionamento social do indivíduo: a eventual patologia de cada indivíduo - escrevia - pode ser temporariamente ocultada pelo funcionamento social do indivíduo. Em anos mais recentes, outro psicanalista italiano, Giuseppe Di Chiara (1999), falou em síndromes psicossociais: situações capazes de desempenhar funções defensivas patológicas, comportamentos coletivos que geram mal-estares futuros e previsíveis. O narcisismo, por exemplo, pode se desenvolver como síndrome 
psicossocial quando se constitui como defesa do grupo social na direção do egoísmo, da satisfação hedonista e da competitividade. Quando o equilíbrio defensivo fundamentado na "socialização" (entendida como "tentativa de ocultação da própria patologia individual no social") se rompe; quando eventos de caráter traumático massivo perturbam esse equilíbrio; ou quando, mais simplesmente, o indivíduo se encontra momentaneamente sozinho, sem cobertura, não mais protegido pela casca da socialização, o sofrimento pode aparecer e assumir as formas mais ou menos específicas. Formas que - ultrapassado certo patamar acabam coincidindo com o que os clínicos e os nosógrafos identificam como distúrbio codificado pelas modernas classificações psiquiátricas. O distúrbio que hoje se espalhou sobretudo nas sociedades avançadas é indubitavelmente a depressão. Mas a depressão de que estamos falando nessa expansão extraordinária, desnaturou-se, perdeu suas características tradicionais e se elevou à categoria de entidade mítica. Uma depressão que, com base nas características de gravidade (em sentido quantitativo) e duração, é codificada pela nosografia psiquiátrica como Transtorno Depressivo Maior ou como Transtorno Distímico. Uma depressão que a nosografia psiquiátrica atual descreve como sempre igual a si mesma, sem nenhuma atenção para a qualidade da experiência depressiva: vale dizer para os diversos modos em que se pode estar deprimido. Se, de fato, a adoção de critérios diagnósticos cada vez mais caracterizados pelas exigências de ateoricidade, objetividade e mensuração quantitativa facilitou o uso do diagnóstico e aumentou a concordância entre os clínicos, por outro lado criou o problema de não saber mais direito do que se está diagnosticando. Em suma, na nosografia contemporânea teve lugar (e, portanto, também na percepção do clínico que adotar acriticamente essa abordagem) um verdadeiro processo de homogeneização da depressão. A vasta gama de modos diferentes de viver a própria depressão deu lugar para uma espécie de "geléia" depressiva indiferenciada que pode ser espalhada nos suportes mais diferentes. Assim uma única e monumental entidade clínica se parece cada vez mais a uma galáxia que compreende todas as formas de sofrimento patológico, mas que inclui ainda muitas formas de normal infelicidade. Uma normal infelicidade que se origina pelo registro da diferença existente entre como somos e como gostaríamos de ser. Por isso a depressão se tornou - como afirma Elisabeth Roudinesco (1999) - a epidemia psíquica das sociedades democráticas: “... a sociedade depressiva não quer mais ouvir falar nem de senso de culpa, nem de intimidade, nem de consciência, nem de desejo, nem de inconsciente". Uma depressão não mais fundamentada nas experiências que, para mais de um século, sustentaram o paradigma da verdadeira e mais profunda depressão: a melancolia. A experiência da culpa marcou desde sempre a depressão por excelência (a melancolia). Tanto que quem se questionou sobre o sentido da experiência da culpa na depressão colocou à luz uma continuidade profunda entre cultura ocidental e 
psicopatologia. Uma relação que pode acolher as diferentes manifestações que a depressão assume em culturas diferentes da nossa. Evelyne Pewzner (1996) afirmou que "a linguagem da loucura sempre acaba sendo o eco mais ou menos distante e deformado de outra linguagem que, sem saber, serve como sua referência e suporte". Se é verdade que os grandes temas que se expressavam na depressão melancólica representavam o eco de uma série de grandes temas pertencentes à nossa tradição cultural (pecado, culpa, expiação) hoje, diante do desvio de paradigma que a depressão veio a enfrentar, é preciso reconsiderar a continuidade entre cultura e patologia. Com que aspectos de nossa cultura estão relacionados os temas que despontam na galáxia depressiva mítica que nos envolve como o ar que respiramos?

\section{Clínica do vazio}

Em 1983, Franz Alexander fazia o balanço de seus quarenta anos de trabalho como psicoterapeuta. Neurose, ansiedade, conflitos - escrevia - não são mais visíveis como em outros tempos: “... vejo, no entanto, mais pessoas se queixando de depressão". Contudo, essa depressão consiste no fato que as pessoas "não têm emoções, sentem-se vazias, estão profundamente frustradas e insatisfeitas (...) O que parece estranho é uma relativa falta de ansiedade e de sentimento de culpa, apesar da gravidade da síndrome. Esse fato, unido à ausência de sentimentos, dá uma impressão de irrealidade".

A ausência de culpa era motivo de surpresa. Hoje já não é assim. Em 1999, Nancy McWilliams confirma o que Lowen havia observado dezesseis anos antes. Um número cada vez maior de pacientes não descreve mais problemas que possam ser ligados a um conflito (segundo a tradição freudiana), mas se queixa de uma "vaga sensação de vazio, de ausência de significado, de dificuldade para definir a si próprios e em gostar de si mesmos e um sentimento de inveja em relação às outras pessoas, que se presume desfrutem disso tudo". É evidente como essas novas formas depressivas não pertencem à tradicional constelação da depressão (culpa - inibição - desaceleração - persecutoriedade interior) quanto, antes, à constelação daquelas depressões que a psiquiatria clínica e a nosografia chamam "atípicas": depressões atípicas que agora, porém, se tornaram típicas. Formas depressivas que se agregam em torno de duas constelações fundamentais de experiências: uma primeira constelação constituída por disforia - raiva solidão - vazio e que afunda as raízes em uma disposição de personalidade da área borderline; uma segunda constelação, organizada em torno das experiências de vazio - insuficiência - desilusão - vergonha, que se inscreve no âmbito da per- 
sonalidade narcísica. Nesse sentido, a epidemia depressiva poderia ser considerada como o invólucro exterior de algumas vicissitudes psicopatológicas em disposições de personalidade que pertencem à área borderline e narcísica. Duas disposições de personalidade cada vez mais freqüentes que parecem estreitamente com aquela perturbação da cultura da infância que levou à sua monumentalização. Ao elenco dos eventos traumáticos infantis que são correlacionados com o desenvolvimento das patologias de personalidade, da área borderline e narcisista, deveria ser acrescentado o trauma relativo ao aprisionamento na condição de Sua majestade a criança que impede de encontrar e pôr à prova as fronteiras da própria identidade.

No que tange à área borderline, recorreu-se a muitos termos para descrever a afetividade "depressiva" borderline: tédio, anedonia, sentimentos de futilidade e sobretudo de vazio interior. Uma condição de fundo atravessada por sentimentos de irritação, disforia, tendência às queixas, experiências de despersonalização auto e halopsíquica e ocasionalmente por acessos de raiva até violenta. Não se trata apenas de uma diferença de quantidade em relação à tradicional constelação depressiva. Estamos diante de uma diferente qualidade da experiência. Muitos estudos, até de caráter empírico, colocaram à luz a relevância dessa diferença qualitativa centrada predominantemente no relevo da constelação afetiva vazio crônico - solidão - disforia - raiva (Gunderson, Phillips, 1991). Em extrema síntese, a depressão borderline se diferencia da depressão clássica pela qualidade dos afetos em jogo, mas também pelo caráter difuso e crônico da experiência depressiva. Uma experiência não delimitável em fases, caracterizada ademais por uma variabilidade elevada por uma reatividade quase atmosférica aos eventos e às relações.

No âmbito da psicopatologia narcisista de personalidade, a depressão se caracteriza, ao contrário, por um doloroso senso de inconsistência, irrealidade e vazio. Em lugar da plenitude de um sentimento depressivo centrado na culpa, abrese um precipício. Na personalidade narcísica, a depressão é sempre latente: toda organização narcisista da personalidade vive constantemente sob a ameaça da queda. A ponto de tornar necessário um trabalho ininterrupto de hipercompensação por meio dos mecanismos de auto-regulação e manutenção da auto-estima que sustentam o delicado equilíbrio do paciente narcisista. Um pouco como funciona o queimador que aquece o ar e permite que um aeróstato mantenha a cota. Quando os complicados processos de auto-regulação, que talvez tenham sustentado por muito tempo o funcionamento de um grandioso self narcísico, entram em crise por um motivo qualquer, a estrutura range: o aeróstato perde altura. Vêm à baila sintomas vagos, porém persistentes: uma sensação subjetiva de inconsistência e vazio. Um vazio que corre o risco de se tornar uma voragem aberta sobre a própria identidade e sobre o próprio valor. Esses primeiros rangidos podem 
ser o prelúdio de uma condição que a clínica psiquiátrica define como "depressão". No entanto, mais uma vez, uma depressão que transborda do seu paradigma tradicional; uma depressão que não se inscreve numa dinâmica fundamentada na agressividade e na culpa, que não recorre à dimensão da culpa para recuperar ao menos o sentido de ter sido artífice do próprio destino. Mas uma depressão em que, impotentes, assiste-se à ruína das próprias ilusões megalomaníacas. Aquele trono se transformou numa armadilha, pois não permitiu que nos arriscássemos na vida. Decepção, vergonha, humilhação, inferioridade, desgosto, desespero pelo tempo perdido: queda da máscara do narcisismo, a pessoa sente-se desnuda, exposta à própria impotência, fragilidade e dependência.

\section{Referências}

Alexander, F. The medical value of psychoanalysis. New York: International Universities Press, 1984.

Aulagnier, P. La violence de l'interpretation. Paris: PUF,1975.

Bauman, Z. Liquid modernity. Cambridge: Polity Press, 2000. . Identity. New York: Polity Press, 2003.

Benasayag, M.; Schmit, G. Les passions tristes. Souffrance psychique et crise social. Paris: La Dècouverte, 2003.

Cunningham, H. Children and childhood in Western society since 1500. New York: Longman, 1995.

Di Chiara, G. Sindromi psicosociali. La psicoanalisi e le patologie sociali. Milano: Raffaello Cortina Editore, 1999.

Ehrenberg, A. La fatigue d'être soi. Depression et società. Paris: Jacob, 1998.

FÉDIDA, P. Des bienfaits de la dèpression. Eloge de la psychothèrapie. Paris: Jacob, 2001.

Fraiberg, S.; Adelson, E.; Shapiro, V. Ghosts in the nursery: a psychoanalytic approach to the problem of impaired infant-mother relationships. J. Amer. Acad. Child Psychiat., New Haven, n. 14, p. 387-422, 1975.

FReUd, S. (1914). On narcissism: an introduction. In: SE. London: Hogarth Press, 1957. v. XIV

Gaddini, E. (1984). Se e come sono cambiati i nostri pazienti fino ai nostri giorni. In: Scritti. Milano: Cortina, 1989.

Gunderson, J.G.; Phillips, K. A current view of the interface between borderline 
personality disorder and depression. Am. J. Psychiatry, Arlington, n. 148, p. 967-975, 1991.

Guyotat, J. Mort-naissance et filiation. Paris: Masson, 1980.

Lipovetsky, G. L'ére du vide. Essais sur l'individualism contemporain. Paris: Gallimard, 1983.

McWilliams, N. Psychoanalytic Case Formulation. New York: Guilford, 1999.

Morin, E. L'esprit du temps. Lamnay: Grasset, 2002.

Pewzner, E. L'homme coupable. La folie et la faute en Occident. Paris: Odile Jacob, 1996.

Roudinesco, E. Pourquoi la psychanalyse? Paris: Fayard, 1999.

Tснекноv, A. Some essays. Leiden: Brill, 1960.

\section{Resumos}

(Contrato narcisista y clinica del vacío)

En la sociedad occidental la relación entre las generaciones es modulada por un pacto narcisista implicito. Las característica de este pacto fueron bien descriptos por Piera Aulagnier y, antes de ella, por Freud en su Introducción al narcisismo. En ese ensayo, Freud describe la actitud de los padres en relación a sus hijos. Los padres claman para sus hijos la derogación de todas las leyes de la naturaleza y de la sociedad (que limitan su propio narcisismo). Enfermedad, muerte, renuncia al placer, restricciones, no deben alcanzar sus bebes. Sus bebes aspiran ser "Su majestad el bebe".

Las "leyes de la naturaleza y de la sociedad" son hoy muy diferentes en relación a la época de Freud. En la sociedades occidentales, el niño realmente se torno "Su majestad el bebe". ¿Que relación existe entre ese nuevo pacto narcisista y las nuevas formas de patología que caracterizan la sociedad occidental? ¿La condición borderline y la depresión endémica tiene alguna relación con esa nueva condición cultural y social en la infancia?

Palabras clave: Psicopatología, depresión, narcisismo, borderline

(Le contrat narcissiste et la clinique du vide)

Dans la société occidentale, le rapport entre les générations est façonné par un pacte narcissiste implicite. Les caractéristiques de ce pacte ont été décrites par Piera Aulagnier et, même avant, par Sigmund Freud dans Sur le narcissisme: une introduction. Dans cet essai, Freud décrit l'attitude des parents par rapport à leurs enfants. Les parents plaident pour leurs enfants l'abrogation de toutes les lois de la 
nature et de la société (qui limitent leur propre narcissisme). Maladie, mort, renonciation au plaisir, restrictions ne devraient pas atteindre leurs bébés. Leurs bébés aspirent à être "Sa Majesté le Bébé".

Les "lois de la nature et de la société" sont actuellement très différentes de celles du temps de Freud. Dans les sociétés occidentales, l'enfant est vraiment devenu "Sa Majesté le Bébé".

Quel pourrait être le rapport existant entre ce nouveau pacte narcissique et les nouvelles modalités de psychopathologie qui caractérisent la société occidentale? La condition borderline et la dépression endémique gardent-elles des rapports avec cette nouvelle condition culturelle et sociale dans l'enfance?

Mots clés: Psychopathologie, dépression, narcissisme, borderline

(Narcissistic contract and the clinic of the void)

In Western society the relationship between one generation and the next is modulated by an implicit narcissistic pact. The characteristics of this pact were well described by Piera Aulagnier and, before her, by Sigmund Freud himself, in On narcissism: an Introduction. There Freud described the attitude of parents toward their children. Parents hope that all the laws of nature and society (which limited their own narcissism) will be abrogated for their children. In other words, death, the renouncement of pleasure, and other restrictions will not affect their little ones.

Today the "laws of nature and society" are very different from those in Freud's time. In Western societies, children have truly become "[Their] Majesty the Baby." What relationship can be seen between this new narcissistic pact and the more recent forms of psychopathology that characterize Western society today? Do borderline condition and epidemic depression have some relationship with this current cultural and social condition in childhood?

Key words: Psychopathology, depression, narcissism, borderline

Versão inicial recebida em dezembro de 2006 Versão aprovada para publicação em outubro de 2007

\section{Mario Rossi Monti}

Professor Titular de Psicologia Clínica do Istituto di Psicologia della Università di Urbino (Urbino, Itália); psiquiatra; psicanalista da Società Psicoanalitica Italiana (IPA)

Via Ubaldini 17

60100 Urbino, Itália

e-mail: rossimonti@alice.it 